\title{
Presence of monoclonal T-cell populations in B-cell post-transplant lymphoproliferative disorders
}

\author{
Hazem AH Ibrahim ${ }^{1}$, Lia P Menasce ${ }^{2}$, Sabine Pomplun ${ }^{3}$, Margaret Burke $^{4}$, Mark Bower ${ }^{5}$ \\ and Kikkeri N Naresh ${ }^{1}$
}

\author{
${ }^{1}$ Department of Histopathology, Hammersmith Hospital and Imperial College, London, UK; ${ }^{2}$ Department of \\ Histopathology, The Christie Hospital, Manchester, UK; ${ }^{3}$ Department of Histopathology, King's College \\ Hospital, London, UK; ${ }^{4}$ Department of Histopathology, Harefield Hospital, Middlesex, UK and ${ }^{5}$ Department \\ of Oncology and HIV Medicine, Chelsea Westminster Hospital, London, UK
}

\begin{abstract}
As has been previously shown, the lack of immune surveillance plays a major role in the unchecked proliferation of Epstein-Barr virus (EBV)-infected B cells in the pathogenesis of B-cell post-transplant lymphoproliferative disorders. We hypothesised that the lack of immune surveillance should possibly also affect T cells, and this should lead to subsequent emergence of T-cell clones. The presence of both B- and T-cell clones in post-transplant lymphoproliferative disorders samples has rarely been demonstrated in the past. We systematically evaluated 26 B-cell post-transplant lymphoproliferative disorder, 23 human immune deficiency virus-associated B-cell lymphoma and 10 immune-competent diffuse large B-cell lymphoma samples for B- and T-cell clonality (polymerase chain reaction and heteroduplex analysis using BIOMED-2 protocol), T-cell subsets (immunohistochemistry) and EBV association (in situ hybridisation using EBER). One-half of B-cell posttransplant lymphoproliferative disorders showed evidence of monoclonal T-cell expansion, and among the T cells present in the tissue samples, CD8-positive cells predominated. Although $9 / 13(69 \%)$ B-cell posttransplant lymphoproliferative disorders with the presence of monoclonal T-cell population had a CD4:CD8 ratio of $\leq 0.4,0 / 13$ of the cases without monoclonal T-cell expansion had a ratio $\leq 0.4(P=0.002)$. Only $2 / 26$ $(8 \%)$ demonstrated significant cytological atypia in the CD3/CD8-positive cells. There was no association between EBV and presence of T-cell clones. T-cell clones were not identified in lymphomas other than B-cell post-transplant lymphoproliferative disorders. Among 53.8\% cases of EBV-positive B-cell post-transplant lymphoproliferative disorders with associated clonal expansion of T-cells tested, none had EBV-positive T cells. We conclude that half of B-cell post-transplant lymphoproliferative disorders are associated with clonal expansion of CD8-positive T cells, most of which do not amount to the coexistence of a T-cell post-transplant lymphoproliferative disorders.
\end{abstract}

Modern Pathology (2011) 24, 232-240; doi:10.1038/modpathol.2010.186; published online 10 September 2010

Keywords: B-cell post-transplant lymphoproliferative disorders; EBV; T-cell clonality

Post-transplant lymphoproliferative disorders are similar to other immunodeficiency-related lymphomas in some aspects: an overwhelming majority are derived from B cells; a far higher proportion are nonHodgkin's lymphomas (as compared with classical Hodgkin's lymphoma); they originate usually in

Correspondence: Professor KN Naresh, MD, FRCPath, Department of Histopathology, Hammersmith Hospital and Imperial College, Du Cane Road, London W12 0HS, UK.

E-mail: k.naresh@imperial.ac.uk

Received 2 June 2010; revised 23 July 2010; accepted 28 July 2010; published online 10 September 2010 extranodal sites but rarely affect skin; and behave aggressively and frequently harbour the EpsteinBarr virus (EBV) genome. ${ }^{1,2}$ Although most are highgrade B-cell non-Hodgkin's lymphomas, a few are classical Hodgkin's lymphomas. Rare cases have also been shown to be either of T- or NK-cell lineages. T-cell neoplasms constitute $10-15 \%$ of all post-transplant lymphoproliferative disorders and about $75 \%$ of T-cell post-transplant lymphoproliferative disorders have been shown to be negative for EBV and to behave more aggressively. ${ }^{1-5}$ Posttransplant lymphoproliferative disorders harbouring both $\mathrm{B}$ - and T-cell clones in the same patient are 
Table 1 Summary of literature on PTLD cases (case reports on single cases) harbouring both T- and B-cell clones

Case harbouring both T- and B-cell clones

Metachronous T- and B-cell post-transplant lymphoproliferative disorders

Concurrent T- and B-cell post-transplant lymphoproliferative disorders at different sites

Simultaneous presence of EBV-positive B-cell post-transplant lymphoproliferative disorders and T-cell post-transplant lymphoproliferative disorders in the same patient

Cutaneous EBV-driven B-cell post-transplant lymphoproliferative disorders with concomitant peripheral blood T-cell clones

Both B- and T-cell clones in the same lesion
Reference

Yin et al; ${ }^{5}$ Morovic et $a l^{11}$

Nelson et $a l^{10}$

Chuhjo et $a l^{6}$

Frankel et $a l^{8}$

Hollingsworth et al; ${ }^{9}$ Euvrard et $a l^{7}$

Both B- and T-cell clonal populations in a polymorphic post-transplant lymphoproliferative disorders Leon et al ${ }^{13}$

extremely rare and there are only a few cases reported in the literature so far. ${ }^{5-13}$ EBV plays an important role in driving the proliferation (Table 1).

As has been shown previously, the lack of immune surveillance plays a major role in the proliferation of unchecked EBV-infected B cells in the pathogenesis of post-transplant lymphoproliferative disorders, with subsequent development of B-cell lymphoproliferation. ${ }^{14}$ We hypothesised that the lack of immune surveillance should possibly also affect $\mathrm{T}$ cells, and this should lead to subsequent emergence of T-cell clones. From the previous literature, it appears that post-transplant lymphoproliferative disorders, which demonstrate both $\mathrm{B}$ - and T-cell clones, are a rare phenomenon. To test whether this was a more frequent phenomenon, we systematically evaluated a relatively large cohort of B-cell post-transplant lymphoproliferative disorders for the presence of expanded T-cell clones. We have compared B-cell post-transplant lymphoproliferative disorders with human immunodeficiency virus (HIV)-associated aggressive B-cell lymphomas and diffuse large B-cell lymphomas in the immunecompetent individuals. We further attempted to characterise the clonal $\mathrm{T}$ cells present in the B-cell post-transplant lymphoproliferative disorders and to evaluate the impact of EBV association with the presence or absence of T-cell clones.

\section{Materials and methods}

\section{Selection of Cases}

We analysed tumour samples from 26 B-cell posttransplant lymphoproliferative disorders, 24 HIVassociated aggressive B-cell lymphomas and 10 diffuse large B-cell lymphomas in the immunecompetent individuals for B- and T-cell clonality. Ten samples of reactive lymph nodes and 10 samples of DNA from normal peripheral blood mononuclear cells were also tested.

\section{Tissue Microarray}

Tissue microarrays were constructed with 2-3 representative $1-\mathrm{mm}$ tissue cores from each case using a manual tissue arrayer. Serial 2 - $\mu$ m-thick sections were cut from tissue microarray blocks.

\section{Immunohistochemical Staining}

The slides were stained with antibodies to CD45, CD20, CD30, CD15, CD10, CD3, CD4, CD8, BCL2, BCL6, MUM1 and CD138 using standard procedures on BOND-MAX automated immunohistochemistry system (Leica Microsystems, New Castle, UK).

\section{In Situ Hybridisation}

mRNA in situ hybridisation with EBER, $\kappa$ and $\lambda$ probes was carried out using BOND-MAX automated in situ hybridisation system (Leica Microsystems). The system employs fluorescein-conjugated oligonucleotide probes. Probe hybridisation is followed by the application of anti-fluorescein antibody and other procedures leading to signal detection as suggested by the manufacturer.

\section{Combined Immunohistochemistry and In Situ Hybridisation}

In situ hybridisation using the EBER probe and with diaminobenzidine as the chromogen was performed on paraffin sections using the Bond immunostainer according to the manufacturer's protocol. This was followed by immunohistochemistry for CD3 using Bond polymer AP Red detection kit (Leica Microsystems).

\section{Polymerase Chain Reaction}

DNA was extracted from formalin-fixed paraffinembedded tissues using a commercially available kit (DNeasy Blood \& Tissue Kit; Qiagen, Crawley, West Sussex, UK). Briefly, two $15-\mu \mathrm{m}$ sections were cut and placed in $1.5 \mathrm{ml}$ Eppendorf tubes. Blades were changed in between the samples to avoid cross-contamination. Sections were deparaffinised and then incubated with proteinase $\mathrm{K}$ and lysis buffer according to the Qiagen protocol 
in a shaking water bath at $55^{\circ} \mathrm{C}$ overnight. The remaining steps were according to the manufacturer's protocol leading to the elution of DNA. The concentration of the DNA obtained was measured using the Nanodrop 1000 spectrophotometer. A multiplex polymerase chain reaction (PCR) for control genes was performed to ascertain the adequacy and the quality of DNA using BIOMED primers $^{15}$ (Invitrogen, Paisley, UK). Cases that had amplicons of $>200 \mathrm{bp}$ in size were used subsequently for clonality assessment.

All cases were investigated for T-cell receptor gene rearrangements (TCR $\beta, T C R \gamma$ and TCR $\delta$ gene rearrangements) and for $\mathrm{B}$-cell receptor gene rearrangements (IGH, IG $\kappa$ and $I G \lambda$ gene rearrangements). The BIOMED-2 PCR protocol was followed with minor modifications. ${ }^{16}$ The test was performed in duplicates. For every run, a positive control (DNA from a known positive case, which had earlier demonstrated a clear monoclonal PCR product), a negative DNA control and a negative control (master mix with no DNA) were used. The Perkin Elmer GeneAmp PCR system 2400 thermal cycler was used to carry out all PCR reactions. The samples were initially denatured at $95^{\circ} \mathrm{C}$ for $10 \mathrm{~min}$, followed by 35 cycles of amplification of $45 \mathrm{~s}$ at $95^{\circ} \mathrm{C}, 30 \mathrm{~s}$ at $64^{\circ} \mathrm{C}$ and $45 \mathrm{~s}$ at $72^{\circ} \mathrm{C}$, and the programme was then ended with final extension at $72^{\circ} \mathrm{C}$ for $10 \mathrm{~min}$. All PCR products were subjected to electrophoresis in $2 \%$ agarose gel for $45-60 \mathrm{~min}$ at $100 \mathrm{~V}$ and visualised using an ultraviolet gel imager (Alpha Innotech, Gabon, UK).

Once the presence of products was confirmed, heteroduplex analysis was carried out according to the standardised protocol of BIOMED-2. Briefly, PCR products were denatured at $95^{\circ} \mathrm{C}$ for $5 \mathrm{~min}$, and then re-annealed at $4^{\circ} \mathrm{C}$ for $60 \mathrm{~min}$. Seven microlitres of each product were mixed with $2 \mu \mathrm{l}$ non-denaturing Blue/Orange loading dye, $6 \times$ (Promega), and then subjected to electrophoresis in a $10 \%$ polyacrylamide Novex TBE Precast gel (Invitrogen) using (XCell SureLock ${ }^{\mathrm{TM}}$ Mini-Cell; Invitrogen) in $1 \times$ diluted-TBE running buffer $(10 \times$; Invitrogen $)$ for $1 \mathrm{~h}$ at $100 \mathrm{~V}$. The products were visualised through staining with Sybersafe in TBE buffer for $10 \mathrm{~min}$ followed by washing twice in TBE buffer and then imaged using an ultraviolet gel imager (Alpha Innotech).

\section{Analysis of Gene Rearrangements}

The results were analysed as being: monoclonal, when 1-2 dominant bands within the expected size range were identified either alone or seen with a background of multiple weaker bands or smear; oligoclonal, when there were three or more bands, which may be superimposed on a polyclonal background; polyclonal, when there were either a ladder of bands 10-20 or a smear over the expected size range; and no signals when no products or only weak bands outside the expected size range were identified. ${ }^{17}$

\section{Statistical Analysis}

Statistical correlations were performed using $\chi^{2}$ tests to evaluate the differences between cases with the presence or absence of T-cell clones and EBV association, and between the presence or absence of T-cell clones and cases having a CD4:CD8 ratio of $\leq 0.4$ or $>0.4$, using the SPSS 17.0 software. All tests were two-sided and a $P$-value less than 0.05 was considered significant.

\section{Results}

\section{Clinical Characteristics}

All post-transplant lymphoproliferative disorders samples were classified according to the current WHO classification. ${ }^{18}$

Among B-cell post-transplant lymphoproliferative disorders, 17 (66\%) were men. The age ranged from 2 to 80 years, with a median age of 48 years. Among HIV-associated aggressive B-cell lymphomas, 22 $(92 \%)$ were men. The age ranged from 26 to 66 years, with a median age of 41 years. Five $(50 \%)$ of the diffuse large B-cell lymphomas in the immunecompetent individuals were men and the age ranged from 27 to 83 years, with a median age of 43 years.

\section{Morphology and Phenotype}

Among B-cell post-transplant lymphoproliferative disorders samples, 1, 9 and 16 were classified as early lesions (plasmacytic hyperplasia), polymorphic post-transplant lymphoproliferative disorders and monomorphic B-cell post-transplant lymphoproliferative disorders, respectively. Among HIV-associated aggressive B-cell lymphomas, 9, 14 and 1 were Burkitt's lymphoma, diffuse large B-cell lymphoma and polymorphic post-transplant lymphoproliferative disorders-like lesion, respectively.

\section{B-cell Clonality Testing by Investigating for $I G H, I G \kappa$ and $I G \lambda$ Gene Rearrangements}

Among B-cell post-transplant lymphoproliferative disorders, 22/26 (84.6\%) showed monoclonal B-cell expansion (15/16 monomorphic B-cell posttransplant lymphoproliferative disorders and 7/9 polymorphic post-transplant lymphoproliferative disorders). The case of plasmacytic hyperplasia and 2/9 polymorphic lesions showed polyclonal B-cell expansion (Table 2). The case of monomorphic B-cell post-transplant lymphoproliferative disorders that did not show evidence of monoclonal B-cell expansion by PCR was $\kappa$-light chain restricted on in situ hybridisation, which was used as a surrogate 
Table 2 PCR reactions for the presence of clonal B- and T-cell populations among B-cell post-transplant lymphoproliferative disorders

\begin{tabular}{|c|c|c|c|c|c|c|c|c|c|c|c|c|c|c|c|c|}
\hline \multirow[t]{2}{*}{ Cases } & \multirow[t]{2}{*}{ Diagnosis } & \multicolumn{7}{|c|}{ B-cell clonality—primer pairs } & \multicolumn{6}{|c|}{ T-cell clonality—primer pairs } & \multicolumn{2}{|c|}{ Clonality } \\
\hline & & $\begin{array}{c}\text { FR1/ } \\
\text { JHC }\end{array}$ & $\begin{array}{c}F R 2 / \\
\text { JHC }\end{array}$ & $\begin{array}{l}\text { FR3/ } \\
\text { JHC }\end{array}$ & $\begin{array}{c}\text { DH 1-6/ } \\
\text { JHC }\end{array}$ & $\begin{array}{c}\mathrm{DH} / \mathrm{I} \\
\mathrm{JHC}\end{array}$ & $\begin{array}{c}V \kappa 1 / 6-7 / \\
J \kappa 1-4 \text { and } 5\end{array}$ & $I G L$ & $T C R G(A)$ & $T C R G(B)$ & $\operatorname{TCRB}(A)$ & TCRB (B) & TCRB $(C)$ & TCRD & B cell & T cell \\
\hline 1 & PM & - & - & - & MC & MC & PC & PC & $\mathrm{MC}(\mathrm{W})$ & PC & - & - & - & - & MC & MC \\
\hline 2 & Early lesion & PC & PC & PC & PC & $\mathrm{PC}$ & $\mathrm{PC}$ & $\mathrm{PC}$ & PC & PC & $\mathrm{PC}$ & $\mathrm{PC}$ & PC & PC & PC & PC \\
\hline 3 & MM-plasmacytoma & MC (W) & - & - & OC & - & MC & - & PC & PC & $\mathrm{PC}$ & PC & PC & PC & MC & PC \\
\hline 4 & MM-lymphoplasmacytic & PC & PC & PC & $\mathrm{PC}$ & - & MC & - & $\mathrm{MC}(\mathrm{W})$ & $\mathrm{PC}$ & - & - & - & - & MC & $\mathrm{MC}$ \\
\hline 5 & MM-DLBCL & - & - & - & PC & - & MC & - & MC (W) & PC & - & - & - & - & MC & MC \\
\hline 6 & MM-DLBCL & - & PC & PC & - & - & MC & - & MC & PC & - & - & - & - & MC & MC \\
\hline 7 & MM-DLBCL & - & $\mathrm{PC}$ & $\mathrm{PC}$ & - & - & MC & - & $\mathrm{MC}$ & - & - & - & - & - & MC & MC \\
\hline 8 & MM-plasmablastic & PC & PC & PC & PC & PC & $\mathrm{PC}$ & PC & $\mathrm{MC}$ & PC & - & - & - & - & $\mathrm{PC}^{\mathrm{a}}$ & MC \\
\hline 9 & $\mathrm{MM}-\mathrm{DLBCL}$ & - & PC & PC & - & PC & $\mathrm{MC}$ & - & $\mathrm{PC}$ & $\mathrm{MC}$ & - & - & - & - & $\mathrm{MC}$ & MC \\
\hline 10 & PM & PC & $\mathrm{PC}$ & $\mathrm{PC}$ & $\mathrm{PC}$ & $\mathrm{PC}$ & $\mathrm{PC}$ & $\mathrm{PC}$ & NA & PC & PC & $\mathrm{PC}$ & PC & PC & PC & $\mathrm{PC}$ \\
\hline 11 & PM & - & PC & MC & - & - & OC & - & DOC & PC & PC & PC & PC & PC & $\mathrm{MC}$ & DOC \\
\hline 12 & PM & - & - & $\mathrm{PC}$ & NA & $\mathrm{PC}$ & $\mathrm{PC}$ & - & PC & $\mathrm{PC}$ & $\mathrm{PC}$ & $\mathrm{PC}$ & $\mathrm{PC}$ & $\mathrm{PC}$ & PC & $\mathrm{PC}$ \\
\hline 13 & MM-DLBCL & - & PC & PC & PC & - & MC & - & PC & MC & - & - & - & - & $\mathrm{MC}$ & MC \\
\hline 14 & MM-DLBCL & - & $\mathrm{PC}$ & MC & PC & - & $\mathrm{PC}$ & $\mathrm{PC}$ & $\mathrm{PC}$ & PC & PC & PC & MC & - & MC & MC \\
\hline 15 & MM-DLBCL & - & $\mathrm{PC}$ & $\mathrm{PC}$ & $\mathrm{PC}$ & PC & $\mathrm{PC}$ & $\mathrm{MC}$ & OC & $\mathrm{PC}$ & PC & $\mathrm{PC}$ & PC & PC & MC & OC \\
\hline 16 & PM & - & $\mathrm{PC}$ & MC & - & - & PC & $\mathrm{MC}$ & PC & OC & PC & PC & PC & PC & $\mathrm{MC}$ & OC \\
\hline 17 & MM-DLBCL & - & $\mathrm{PC}$ & MC & $\mathrm{PC}$ & PC & - & PC & $\mathrm{PC}$ & $\mathrm{PC}$ & $\mathrm{PC}$ & $\mathrm{PC}$ & $\mathrm{PC}$ & $\mathrm{PC}$ & MC & PC \\
\hline 18 & $\mathrm{PM}$ & - & MC & - & - & PC & PC & PC & PC & PC & PC & PC & PC & PC & $\mathrm{MC}$ & PC \\
\hline 19 & MM-DLBCL & - & $\mathrm{PC}$ & $\mathrm{PC}$ & PC & MC & PC & PC & NA & $\mathrm{PC}$ & $\mathrm{MC}$ & PC & - & - & $\mathrm{MC}$ & MC \\
\hline 20 & MM-DLBCL & - & - & $\mathrm{MC}$ & - & MC & - & - & $\mathrm{PC}$ & MC & - & - & - & - & MC & MC \\
\hline 21 & MM-DLBCL & - & PC & PC & - & - & MC & - & $\mathrm{PC}$ & PC & PC & PC & PC & PC & $\mathrm{MC}$ & PC \\
\hline 22 & MM-DLBCL & - & - & $\mathrm{PC}$ & $\mathrm{MC}$ & - & - & - & $\mathrm{PC}$ & $\mathrm{PC}$ & $\mathrm{PC}$ & $\mathrm{PC}$ & $\mathrm{PC}$ & $\mathrm{PC}$ & MC & $\mathrm{PC}$ \\
\hline 23 & $\mathrm{PM}$ & - & - & PC & PC & MC & - & - & $\mathrm{MC}$ & PC & - & - & - & - & $\mathrm{MC}$ & MC \\
\hline 24 & $\mathrm{PM}$ & - & PC & MC & - & - & PC & - & PC & PC & PC & PC & PC & PC & MC & $\mathrm{PC}$ \\
\hline 25 & MM-DLBCL & - & - & $\mathrm{PC}$ & - & - & MC & - & $\mathrm{PC}$ & $\mathrm{PC}$ & PC & $\mathrm{PC}$ & $\mathrm{PC}$ & $\mathrm{PC}$ & MC & $\mathrm{PC}$ \\
\hline 26 & PM & - & $\mathrm{PC}$ & MC & & MC & - & - & PC & PC & PC & PC & PC & PC & $\mathrm{MC}$ & PC \\
\hline
\end{tabular}

Abbreviations: DLBCL, diffuse large B-cell lymphoma; DOC, dominant band in an oligoclonal background; MM, monomorphic post-transplant lymphoproliferative disorder; PM, polymorphic

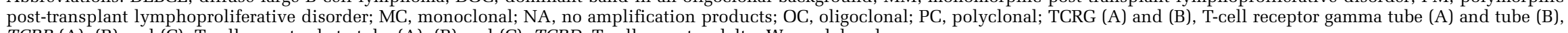
TCRB (A), (B) and (C), T-cell receptor beta tube (A), (B) and (C); TCRD, T-cell receptor delta; W, weak band.

$(-)$ not done as monoclonality was established with other primer pairs.

${ }^{\mathrm{a}}$ The case showed IgK restriction on ISH. 
for the presence of clonal B-cell expansion. All HIVassociated aggressive B-cell lymphoma samples, apart from the B-cell post-transplant lymphoproliferative disorders-like lesion, and all diffuse large B-cell lymphomas in the immune-competent individuals showed monoclonal B-cell expansion.

\section{T-cell Clonality Assessment by Investigating for $T C R \beta, T C R \gamma$ and TCR $\delta$ gene rearrangements}

Among B-cell post-transplant lymphoproliferative disorders, 13 of $26(50 \%)$ showed evidence of monoclonal T-cell expansion. This included two cases of polymorphic post-transplant lymphoproliferative disorders (both with monoclonal B-cell population) and 10 cases of monomorphic B-cell post-transplant lymphoproliferative disorders. One of 26 B-cell post-transplant lymphoproliferative disorders and one of the 10 diffuse large B-cell lymphomas in the immune-competent individuals showed the presence of a dominant amplicon in the background of polyclonal/oligoclonal T-cell expansion suggesting a minor T-cell clone. Two of 26 B-cell post-transplant lymphoproliferative disorders showed oligoclonal T-cell population (Table 2). The other B-cell post-transplant lymphoproliferative disorders samples, all HIV-associated aggressive B-cell lymphomas, nine of diffuse large B-cell lymphomas in the immune-competent individuals, the 10 cases of reactive lymph nodes and all normal peripheral blood mononuclear cell samples did not show evidence of monoclonal T-cell expansion.

\section{Correlation of the Presence of Monoclonal T-cell Populations in B-cell Post-Transplant Lymphoproliferative Disorders with CD4/CD8 Ratio and Other T-cell Characteristics}

All cases of B-cell post-transplant lymphoproliferative disorders with a monoclonal T-cell population showed dominance of CD8-positive cells. Although 9/13 (69\%) B-cell post-transplant lymphoproliferative disorders with the presence of monoclonal T-cell population (not including oligoclonal cases) had a CD4:CD8 ratio of $\leq 0.4$, none of the cases without monoclonal T-cell expansion had a ratio $<0.4 \quad(P=0.002) \quad$ (Figures 1 and 2; Table 3). The morphology of the T-cell population in B-cell

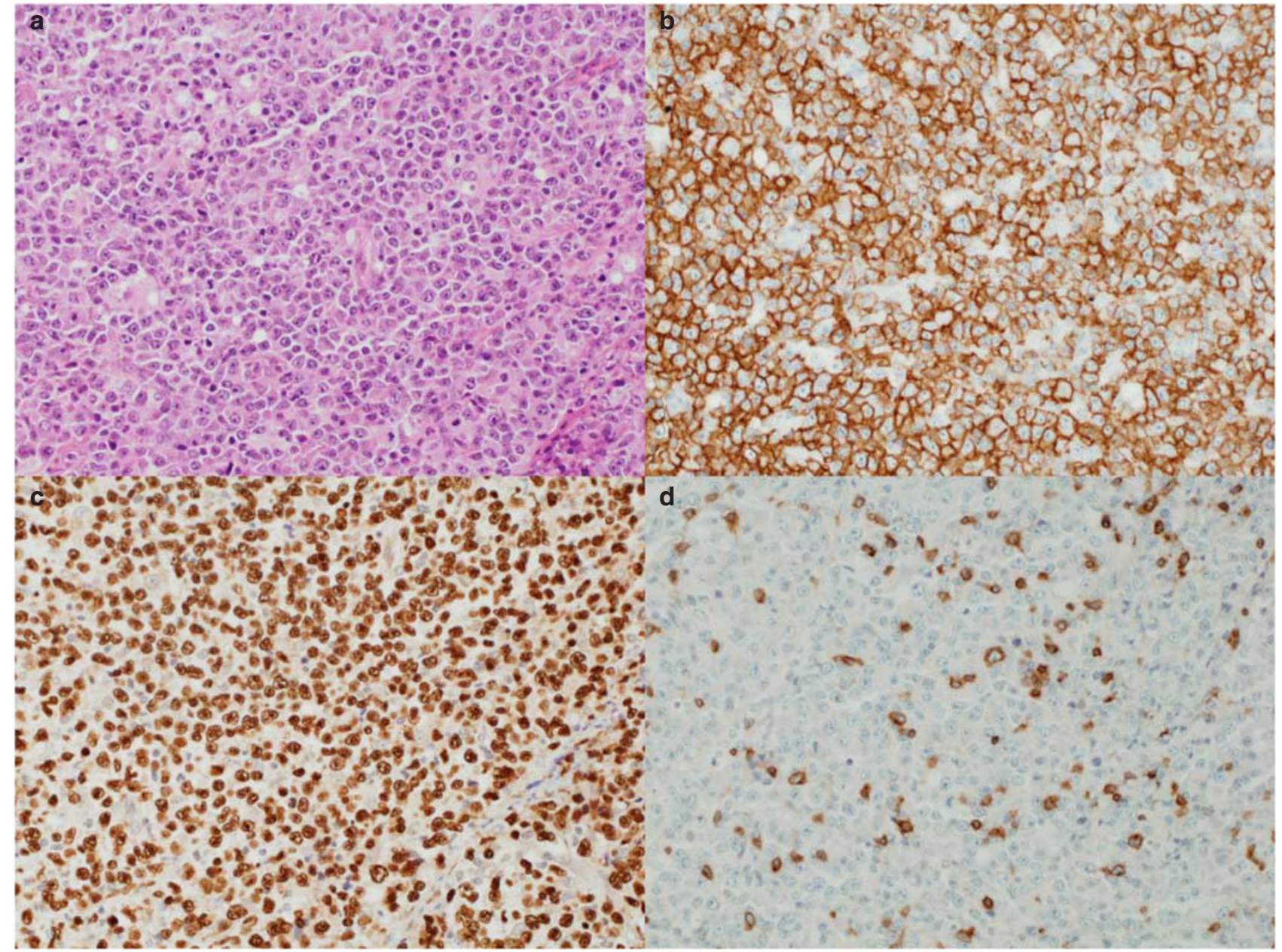

Figure 1 A case of monomorphic B-cell post-transplant lymphoproliferative disorders (H\&E; a) positive for CD20 (b) and EBER (c). Infiltrating T cells are demonstrated by CD3 immunostain (d), and occasionally cells are larger than the rest of the T cells (all images $\times 200$ ). 


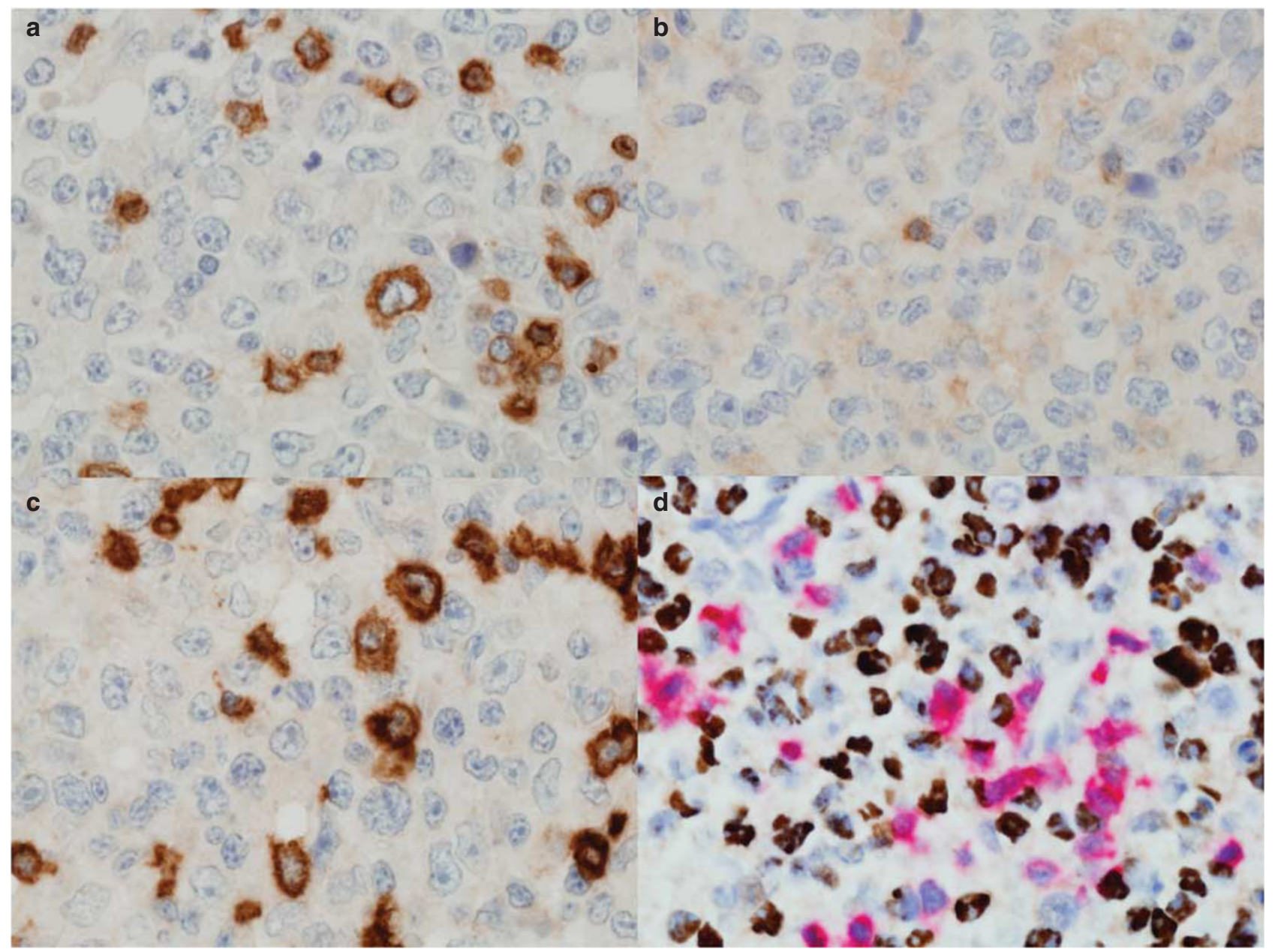

Figure 2 Immunostain CD3 highlights the infiltrating $\mathrm{T}$ cells in the B-cell post-transplant lymphoproliferative disorders sample (a) including occasionally larger and atypical cells. Most of the T cells are negative for CD4 (b) and positive for CD8 (c). Immuno-ISH with CD3 antibody (red colour) and EBER riboprobe (brown colour) shows that the positive cells are mutually exclusive (all images $\times 400$ ).

Table 3 Morphologies, EBV association and CD4:CD8 ratios of cases associated with monoclonal and oligoclonal T-cell populations

\begin{tabular}{|c|c|c|c|c|c|}
\hline & Morphology & CD4:CD8 ratio & $E B V(E B E R)$ & B-cell clonality & T-cell clonality \\
\hline 1 & $\mathrm{PM}$ & 0.2 & Positive & MC & MC (weak) \\
\hline 2 & MM-lymphoplasmacytic & 0.2 & Positive & MC & MC (weak) \\
\hline 3 & MM-DLBCL & 0.2 & Positive & MC & MC (weak) \\
\hline 4 & MM-DLBCL & 0.4 & Negative & MC & MC \\
\hline 5 & MM-DLBCL & 1.6 & Negative & MC & MC \\
\hline 6 & MM-DLBCL plasmablastic & 0.2 & Positive & $\mathrm{PC}^{\mathrm{a}}$ & MC \\
\hline 7 & MM-plasmacytoma & 1.7 & Positive & $\mathrm{MC}$ & $\mathrm{MC}$ \\
\hline 8 & $\mathrm{PM}$ & 1.2 & Positive & MC & DOC (minor clone) \\
\hline 9 & MM-DLBCL & 0.1 & Positive & MC & MC \\
\hline 10 & MM-DLBCL & 0.9 & Positive & MC & MC \\
\hline 11 & MM-DLBCL & 0.3 & Positive & MC & OC \\
\hline 12 & PM & 0.9 & Positive & MC & OC \\
\hline 13 & MM-DLBCL & 0.2 & Positive & MC & $\mathrm{MC}$ \\
\hline 14 & MM-DLBCL & 0.4 & Positive & MC & MC \\
\hline 15 & $\mathrm{PM}$ & 0.4 & Positive & MC & MC \\
\hline
\end{tabular}

Abbreviations: PM, polymorphic post-transplant lymphoproliferative disorder; MM, monomorphic post-transplant lymphoproliferative disorder; DLBCL, diffuse large B-cell lymphoma; PC, polyclonal; OC, oligoclonal; DOC, dominant band in an oligoclonal background, MC, monoclonal.

${ }^{\mathrm{a}}$ The case showed IgK restriction on ISH. 
post-transplant lymphoproliferative disorders with clonal T-cell expansion was revisited. A proportion of the CD3-positive T-cells appeared large and atypical in one case of monomorphic B-cell posttransplant lymphoproliferative disorder. The histological findings in another case suggested features that were compatible with a co-existing T-cell posttransplant lymphoproliferative disorder of small cell type. It showed effacement of the nodal architecture and replacement by a diffuse infiltrate composed of small and some scattered large blastic lymphoid cells. The large cells were positive for CD20 and EBER, and showed $\lambda$-light-chain restriction. The small cells were positive for CD3 and CD8.

Overall, in only six of 26 B-cell post-transplant lymphoproliferative disorders samples CD4-positive cells were seen in excess of CD8-positive cells, and one of these six cases were EBV positive.

\section{Correlation of the Presence of Monoclonal T-cell Populations in B-cell Post-Transplant} Lymphoproliferative Disorders with EBV Association

EBV association was present in 20/26 (77\%) B-cell post-transplant lymphoproliferative disorders. Although 13/15 (86.7\%) B-cell post-transplant lymphoproliferative disorders, which harboured a T-cell clone (including both oligoclonal and monoclonal), were EBV associated, $7 / 11(63.6 \%)$ samples that lacked T-cell clones showed EBV association. This, however, was statistically not significant $(P=0.618)$. Seven cases of the $13(53.8 \%)$ EBV-positive B-cell post-transplant lymphoproliferative disorders with associated monoclonal T-cell expansion were analysable by combined immunohistochemistry and in situ hybridisation (with CD3 antibody and EBER probe) and none of them showed EBV positivity in the CD3-positive T-cell population (Figure 2).

\section{Discussion}

This study, to the best of our knowledge, constitutes the largest series of B-cell post-transplant lymphoproliferative disorders investigated for both B- and T-cell clonality. Our results showed that B-cell posttransplant lymphoproliferative disorders harbour secondary clonal populations additional to the preponderant clonal population that is perceived as being 'neoplastic'. Among B-cell post-transplant lymphoproliferative disorders investigated in our study, $88 \%$ showed monoclonal B-cell population (100\% of monomorphic B-cell post-transplant lymphoproliferative disorders and $78 \%$ of polymorphic post-transplant lymphoproliferative disorders) and this is in agreement with other reports in the literature. ${ }^{19,20}$

One-half of B-cell post-transplant lymphoproliferative disorders, all with documented monoclonal B-cell population showed evidence of monoclonal T-cell expansion. The clonal T-cell expansion in two cases was associated with morphological features that could imply coexistence of neoplastic T-cell post-transplant lymphoproliferative disorders or of an early evolution of T-cell post-transplant lymphoproliferative disorders. The coexistence of both B- and T-cell clones in the same lesion has been previously documented in post-transplant lymphoproliferative disorders, but only as case reports. ${ }^{7,9}$

The reports on coexisting B- and T-cell clones include two with metachronous B-cell post-transplant lymphoproliferative disorders and T-cell post-transplant lymphoproliferative disorders, ${ }^{5,11}$ presence of concurrent T- and B-cell post-transplant lymphoproliferative disorders at different sites, ${ }^{10}$ simultaneous presence of EBV-positive B-cell posttransplant lymphoproliferative disorders and T-cell post-transplant lymphoproliferative disorders, ${ }^{6}$ and a case of cutaneous EBV-driven B-cell posttransplant lymphoproliferative disorders with concomitant peripheral blood T-cell clones. ${ }^{8}$ Two cases of EBV-negative cutaneous anaplastic large-cell lymphoma with dual $\mathrm{T}$ - and $\mathrm{B}$-cell receptor gene rearrangements have also been reported. ${ }^{12}$

Whether the emergence of T-cell clones is triggered by B-cell clones (EBV infected or otherwise) or is secondary to the lack of immune surveillance similar to its impact on EBV-infected B cells is not clear and needs to be elucidated. The lack of immune surveillance secondary to reduced EBVspecific cytotoxic $\mathrm{T}$ cells, due to immunosuppressive drugs, is said to play a major role in promoting the development of uncontrolled proliferation of EBV-infected B cells resulting in the development of B-cell post-transplant lymphoproliferative disorders. ${ }^{14}$ We speculate that a similar lack of immune surveillance might also be responsible for the emergence of T-cell clones.

All cases of B-cell post-transplant lymphoproliferative disorders with a monoclonal T-cell population showed a significant predominance of CD8-positive cells. The finding needs to be further documented using laser capture microdissection to assess the clonality of isolated CD8-positive cells in cases with T-cell clonal expansion or in sorted T-cell subpopulations if fresh tissue is available. Whether an infective agent directly infecting the $\mathrm{T}$ cells plays a role is difficult to substantiate. Among our cases, we found that a majority of B-cell post-transplant lymphoproliferative disorders (77\%) have CD8positive T cells in excess of CD4-positive T cells in the microenvironment. Literature available on this aspect of post-transplant lymphoproliferative disorders is limited. In a small series, it was reported in 1998 that CD4-positive cells predominated over CD8-positive cells among 8/11 post-transplant lymphoproliferative disorders samples. ${ }^{21}$

There has been an occasional report associating the existence of oligoclonal cytotoxic T-cell populations with tumour regression in post-transplant lymphoproliferative disorders. ${ }^{22}$ More recently, higher numbers of tumour-infiltrating $\mathrm{T}$ cells and 
TIA-1 ${ }^{+}$(T-cell intracellular antigen-1) cytotoxic $\mathrm{T}$ cells have been reported to be predictors of favourable outcome in post-transplant lymphoproliferative disorders patients indicating the preservation of antitumour immune responses in these patients. $^{23}$

We excluded the possibility of EBV infecting and driving the T cells. EBV has been found to infect a subset of $\mathrm{T}$ cells that express the viral receptor CD21. ${ }^{4}$ High levels of uncontrolled viral replication are thought to facilitate the entrance of EBV into T cells. ${ }^{5}$ Despite the presence of previous reports, which showed that EBV can infect T cells, in our study none of the seven assessable cases showed evidence of EBV infection in the T-cell population.

In the first five years of transplantation, EBVpositive post-transplant lymphoproliferative disorders predominate over EBV-negative B-cell post-transplant lymphoproliferative disorders. Furthermore, a greater proportion of late-onset B-cell post-transplant lymphoproliferative disorders are EBV negative, and most T-cell post-transplant lymphoproliferative disorders are late onset. ${ }^{1224-26}$ Hence, in the posttransplant setting, EBV-infected B cells appear to have a proliferative advantage.

The presence of 'benign' clonally expanded $\mathrm{T}$ cells or $\mathrm{T}$ cells demonstrating skewed T-cell receptor repertoire in the peripheral blood is known in patients following transplantation. Among patients who have had allogenic stem cell transplantation, these $\mathrm{T}$ cells are of donor origin and are likely to be induced by EBV-infected B cells. ${ }^{27}$ On the other hand, in patients of solid organ transplants like renal transplants, the $\mathrm{T}$ cells are of patient/ recipient origin and represent allo-reactive $\mathrm{T}$ cells against the transplanted organ. The presence of expanded T-cell clones in the peripheral blood has been shown to have a negative impact on the long-term graft function (survival of the transplanted kidney). ${ }^{28}$

Contrary to post-transplant lymphoproliferative disorders, we did not encounter a single case of HIVassociated aggressive B-cell lymphomas with the presence of T-cell clones. During the early course of HIV-1 infection, CD8-positive T cells show a moderate rise, which is transient in most cases, and then decline in parallel with the depletion of CD4positive $\mathrm{T}$ cells. ${ }^{29}$ However, persistent elevation of circulating CD8-positive $\mathrm{T}$ cells with visceral involvement, mainly salivary glands and lung, in response to HIV-1 infection, has been described in certain group of patients. ${ }^{30}$ These are manifested as clonally expanded T-cell populations in the peripheral blood and in the viscera. The clonal expansions can be large and may persist with dominance of specific clones. ${ }^{31-34}$

In summary, our results show that monoclonal expansion of T-cell population occurs frequently in B-cell post-transplant lymphoproliferative disorders and these clonal T-cell populations coexist with monoclonal B-cell population in B-cell post- transplant lymphoproliferative disorders. The T-cell clones seem to arise mainly from CD8-positive $\mathrm{T}$ cells. Whether EBV plays a pivotal role in the emergence of T-cell clones is unclear. It is intuitive to think that EBV and other infective agents possibly play a role in the clonal expansion of CD8-positive T cells. Although the monoclonal T-cell population is cytomorphologically occult in most, rare cases with the presence of morphological atypia may suggest a potential to progression. In such cases, follow-up and clinical correlation could be recommended. More studies are required to validate these findings.

\section{Acknowledgement}

We thank the ministry of high education (Egypt) for funding Dr Hazem Ibrahim.

\section{Disclosure/conflict of interest}

The authors declare no conflict of interest.

\section{References}

1 Kwong YL, Lam CC, Chan TM. Post-transplantation lymphoproliferative disease of natural killer cell lineage: a clinicopathological and molecular analysis. Br J Haematol 2000;110:197-202.

2 Jaffe ES, Harris NL, Stein H, et al. World Health Organization Classification of Tumour: Pathology and Genetics, Tumours of Haematopoietic and Lymphoid Tissues. IARC Press: Lyon, 2001.

3 Costes-Martineau V, Delfour C, Obled S, et al. Anaplastic lymphoma kinase (ALK) protein expressing lymphoma after liver transplantation: case report and literature review. J Clin Pathol 2002;55:868-871.

4 Sivaraman P, Lye WC. EpsteinBarr virus-associated T-cell lymphoma in solid organ transplant recipients. Biomed Pharmacother 2001;55:366-368.

5 Yin CC, Medeiros LJ, Abruzzo LV, et al. EBV-associated B- and T-cell posttransplant lymphoproliferative disorders following primary EBV infection in a kidney transplant recipient. Am J Clin Pathol 2005; 123:222-228.

6 Chuhjo T, Yachie A, Kanegane H, et al. EpsteinBarr virus (EBV)-associated post-transplantation lymphoproliferative disorder simultaneously affecting both B and $\mathrm{T}$ cells after allogeneic bone marrow transplantation. Am J Hematol 2003;72:255-258.

7 Euvrard S, Noble CP, Kanitakis J, et al. Brief report: successive occurrence of T-cell and B-cell lymphomas after renal transplantation in a patient with multiple cutaneous squamous-cell carcinomas. N Engl J Med 1992;327:1924-1926.

8 Frankel AH, Thompson M, Vulliamy T, et al. A T cell clone in association with an EpsteinBarr virus-related B cell lymphoma. Transplantation 1991;52:1108-1109.

9 Hollingsworth HC, Stetler-Stevenson M, Gagneten D, et al. Immunodeficiency-associated malignant lymphoma. Three cases showing genotypic evidence of 
both T- and B-cell lineages. Am J Surg Pathol 1994;18:1092-1101.

10 Nelson BP, Locker J, Nalesnik MA, et al. Clonal and morphological variation in a posttransplant lymphoproliferative disorder: evolution from clonal T-cell to clonal B-cell predominance. Hum Pathol 1998;29: 416-421.

11 Morovic A, Jaffe ES, Raffeld M, et al. Metachronous EBV-associated B-cell and T-cell posttransplant lymphoproliferative disorders in a heart transplant recipient. Am J Surg Pathol 2009;33:149-154.

12 Magro CM, Weinerman DJ, Porcu PL, et al. Posttransplant EBV-negative anaplastic large-cell lymphoma with dual rearrangement: a propos of two cases and review of the literature. J Cutan Pathol 2007; 34(Suppl 1):1-8.

13 Leon JE, Takahama JA, Vassallo J, et al. EBV-associated polymorphic posttransplant lymphoproliferative disorder presenting as gingival ulcers. Int J Surg Pathol 2010; e-pub ahead of print.

14 Baudouin V, Dehee A, Pedron-Grossetete B, et al. Relationship between CD8+ T-cell phenotype and function, EpsteinBarr virus load, and clinical outcome in pediatric renal transplant recipients: a prospective study. Transplantation 2004;77:1706-1713.

15 van Dongen JJ, Langerak AW, Bruggemann M, et al. Design and standardization of PCR primers and protocols for detection of clonal immunoglobulin and T-cell receptor gene recombinations in suspect lymphoproliferations: report of the BIOMED-2 Concerted Action BMH4-CT98-3936. Leukemia 2003;17: 2257-2317.

16 Liu H, Bench AJ, Bacon CM, et al. A practical strategy for the routine use of BIOMED-2 PCR assays for detection of $\mathrm{B}$ - and T-cell clonality in diagnostic haematopathology. Br J Haematol 2007;138:31-43.

17 Hoeve MA, Krol AD, Philippo K, et al. Limitations of clonality analysis of B cell proliferations using CDR3 polymerase chain reaction. Mol Pathol 2000;53: 194-200.

18 Swerdlow SH, Webber SA, Chadburn A, et al. Posttransplant lymphoproliferative disorders In: Swerdlow SH, Campo E, Harris NL, Jaffe ES, Pileri SA, Stein H, Thiele J, Vardiman JW (eds). WHO Classification of Tumours of Haematopoietic and Lymphoid Tissues. IARC: Lyon, France, 2008, pp 343-349.

19 Knowles DM, Cesarman E, Chadburn A, et al. Correlative morphologic and molecular genetic analysis demonstrates three distinct categories of posttransplantation lymphoproliferative disorders. Blood 1995;85:552-565.

20 Vakiani E, Nandula SV, Subramaniyam S, et al. Cytogenetic analysis of B-cell posttransplant lymphoproliferations validates the World Health Organization classification and suggests inclusion of florid follicular hyperplasia as a precursor lesion. Hum Pathol 2007; 38:315-325.
21 Perera SM, Thomas JA, Burke M, et al. Analysis of the T-cell micro-environment in EpsteinBarr virus-related post-transplantation B lymphoproliferative disease. J Pathol 1998;184:177-184.

22 Khatri VP, Baiocchi RA, Peng R, et al. Endogenous CD8+ $\mathrm{T}$ cell expansion during regression of monoclonal EBV-associated posttransplant lymphoproliferative disorder. J Immunol 1999;163:500-506.

23 Richendollar BG, Tsao RE, Elson P, et al. Predictors of outcome in post-transplant lymphoproliferative disorder: an evaluation of tumor infiltrating lymphocytes in the context of clinical factors. Leuk Lymphoma 2009;50:2005-2012.

24 Leblond V, Davi F, Charlotte F, et al. Posttransplant lymphoproliferative disorders not associated with EpsteinBarr virus: a distinct entity? J Clin Oncol 1998;16:2052-2059.

25 Nelson BP, Nalesnik MA, Bahler DW, et al. EpsteinBarr virus-negative post-transplant lymphoproliferative disorders: a distinct entity? Am J Surg Pathol 2000; 24:375-385.

26 Tang MB, Tan ES, Tan SH. Late-onset EpsteinBarr virus-negative post-transplant lymphoproliferative disorder presenting as ulcerated necrotic papules and nodules in a renal transplant patient. Australas J Dermatol 2008;49:100-102.

27 Fujishima N, Hirokawa M, Fujishima M, et al. Skewed $\mathrm{T}$ cell receptor repertoire of Vdelta1(+) gammadelta $\mathrm{T}$ lymphocytes after human allogeneic haematopoietic stem cell transplantation and the potential role for EpsteinBarr virus-infected B cells in clonal restriction. Clin Exp Immunol 2007;149:70-79.

28 Matsutani T, Ohashi Y, Yoshioka T, et al. Skew in T-cell receptor usage and clonal T-cell expansion in patients with chronic rejection of transplanted kidneys. Transplantation 2003;75:398-407.

29 Zolla-Pazner S, Des J, Friedman SR, et al. Nonrandom development of immunologic abnormalities after infection with human immunodeficiency virus: implications for immunologic classification of the disease. Proc Natl Acad Sci USA 1987;84:5404-5408.

30 Itescu S, Brancato LJ, Winchester R. A sicca syndrome in HIV infection: association with HLA-DR5 and CD8 lymphocytosis. Lancet 1989;2:466-468.

31 Smith PR, Cavenagh JD, Milne T, et al. Benign monoclonal expansion of CD8+ lymphocytes in HIV infection. J Clin Pathol 2000;53:177-181.

32 Pantaleo G, Soudeyns H, Demarest JF, et al. Evidence for rapid disappearance of initially expanded HIVspecific CD8+ $\mathrm{T}$ cell clones during primary HIV infection. Proc Natl Acad Sci USA 1997;94:9848-9853.

33 Callan MF, Steven N, Krausa P, et al. Large clonal expansions of CD8+ $\mathrm{T}$ cells in acute infectious mononucleosis. Nat Med 1996;2:906-911.

34 Wilson JD, Ogg GS, Allen RL, et al. Oligoclonal expansions of CD8(+) T cells in chronic HIV infection are antigen specific. J Exp Med 1998;188:785-790. 